\title{
O contexto bilíngue para surdos: escrita e ensino - um estudo de caso
}

\section{The bilingual context for deaf people: writing and teaching - a case study}

\author{
Dayse Grassi ${ }^{*}$ \\ Maria Ceres Pereira
}

Resumo: Atualmente os surdos são reconhecidos como minoria linguística imersa em outras, partilhando o mesmo espaço físico. A comunidade surda possui uma forma peculiar de apreender o mundo, suas experiências são tidas através da visão. A língua de sinais, língua natural dos surdos, apresenta-se em uma modalidade diferenciada da língua portuguesa, pois é uma língua gestual-visual, apresentando uma estrutura gramatical diferenciada. Sendo assim, a língua portuguesa é a segunda língua para os surdos e o aprendizado dessa, pressupõe o aprendizado da língua de sinais. Assim, o contexto bilíngue dos surdos é constituído de forma diferente do contexto bilíngue dos ouvintes, sendo pertinente estudos acerca disso.

Palavras-chaves: Surdos. Bilinguismo. Contexto escolar.

Abstract : Nowadays deaf people are known as linguistic minority immersed in other, sharing the same space. The deaf community has a peculiar way to see the world, its experiences are got through their eyes the body language, the natural language of deaf people, is shown in a different aspect of the Portuguese language because it's a gesture/visual language, which has a different grammar structure. Therefore, the Portuguese language is seen as a second language and its learning, supposes the body language learning. So, the deaf people bilingual context is constituted on a different way of listening students, being important to make researches about that.

Keywords: Deaf people. Bilingualism. Bilingual school.

\footnotetext{
* Mestranda em Letras, Linguagem e Sociedade - UNIOESTE, campus Cascavel. Professora Intérprete de Língua de Sinais da Universidade Tecnológica Federal do Paraná. E-mail: daysegrassi@brturbo.com.br

*** Mestranda em Letras, Linguagem e Sociedade - UNIOESTE, campus Cascavel. Professora Intérprete de Língua de Sinais da Universidade Tecnológica Federal do Paraná.

E-mail: daysegrassi@brturbo.com.br
} 


\section{Introdução}

A Inclusão das diferenças é realidade em várias instituições educacionais no Brasil. Foi a partir da Declaração Mundial de Educação para Todos - documento de referência mundial e orientador do processo da inclusão -, firmada em Jomtien (Tailândia, 1990) em consonância com os postulados produzidos em Salamanca (Espanha, 1994), que destaca em um de seus apontamentos a "[...] importância de uma educação pautada no direito e reconhecimento da língua natural do indivíduo", que o Brasil fez a opção pela política inclusiva. Sendo assim, houve a reestruturação da legislação brasileira, implantando-se a inclusão educacional e social. Algumas leis foram modificadas, dentre elas, as Diretrizes Nacionais para a Educação Especial na Educação Básica (resolução nº. 02/2002 do CNE) e a Lei de Diretrizes e Bases da Educação Nacional (2004), que garante o acesso e a participação de todos no ensino equiparando oportunidades, trazendo as comunidades multiculturais para uma inclusão social de modo que compartilhem culturas e experiências moldando as relações sociais.

A partir disso, as vozes sociais, até então negadas e silenciadas, começam a buscar seu espaço, surgindo os movimentos multiculturais dos quais fazem parte os negros, índios, mulheres, afro descendentes, imigrantes, sertanejos, surdos dentre outras minorias étnicas, que lutam pelos seus direitos civis, maior participação educacional e social, enfatizando, dessa maneira, a "diversidade cultural”.

Assim, os PCN's - Parâmetros Curriculares Nacionais destaca em um de seus volumes a temática da Pluralidade Cultural (1997), salientando a valorização das características étnicas e culturais dos diversos grupos, buscando a superação de todas as formas discriminatórias e excludentes, possibilitando conhecer o Brasil como um país complexo e multifacetado. Cabe aqui ressaltar que valorizar e respeitar as diferenças étnicas e sociais não significa aderir aos valores, mas sim respeitá-los como expressão da diversidade; respeito que é, em si, dever e direito de todo o ser humano.

O primeiro Artigo da Constituição Federal (1988) estabelece as bases para viabilizar a igualdade de oportunidades, e também um modo de sociabilidade que permite a expressão das diferenças e conflitos. Isso é, a pluralidade em que devem valer a liberdade, a sabedoria de conviver com o diferente, tanto do ponto de vista de valores quanto de costumes, crenças religiosas, expressões artísticas, capacidade e limitações. 
De acordo com a Constituição Federal de 1988 (Art. 13, p.15) “[...] a língua portuguesa é o idioma oficial da República Federativa do Brasil”. Porém, vale ressaltar que, no Brasil, conforme Mello (1999) existem 170 línguas indígenas de troncos e famílias diferentes, isso sem mencionar as línguas faladas em comunidades de ascendência italiana, japonesa, coreana, germânica, entre outras, no sul e sudeste do país, sem contar ainda, a língua de sinais da comunidade surda.

Dado o exposto, podemos afirmar que o Brasil é um país complexo, com um plurilinguismo muito significativo. Porém, mesmo diante disso, a língua de status e oficial de instrução continua sendo a língua portuguesa, invisibilizando todas as demais. Dessa forma, percebemos que as minorias linguísticas não têm status oficial, e o primeiro passo para que isso mude é a luta pelo reconhecimento de sua língua e seus direitos enquanto minorias bilíngues. De acordo com Mello (1999), é importante ressaltar que uma sociedade bilíngue não se forma somente a partir do contato entre línguas e culturas, “[...] igualmente importante são as atitudes que as pessoas têm em relação às línguas e aos membros das comunidades minoritárias, bem como às políticas linguísticas a serem adotadas pela comunidade num todo”.

Os surdos são vistos e reconhecidos atualmente como uma comunidade possuidora de língua e cultura própria, tendo o direito de instrução em sua primeira língua, a língua de sinais, com uma educação bilíngue e a presença de um mediador de comunicação, o intérprete de língua de sinais. Tudo isso assegurado pela Lei Federal ${ }^{\circ}$. 10.436, de 24 de abril de 2002, que reconhece a Língua Brasileira de Sinais - Libras, como língua oficial da comunidade surda, com implicações para o acesso bilíngue à informação em ambientes institucionais. Dessa forma, deixa-se de lado a visão clínica que enfatiza apenas a perda auditiva, voltando-se não mais ao termo "deficiente auditivo", mas ao termo "surdo”, visto reconhecer sua língua, identidade e cultura.

\section{O bilinguismo e sua representação para a pessoa surda}

Segundo o Censo Demográfico de 2000, no Brasil existe um total de 5.750 .805 pessoas surdas que enquanto minorias linguísticas buscam o seu espaço, lutando pelos seus direitos e reconhecimento social.

As pessoas surdas atualmente são vistas e reconhecidas como uma comunidade que possui identidade, cultura e língua que lhes são próprios e 
de acordo com Kelman (2008, p.88) “[...] o tema da surdez é hoje abordado como uma manifestação de uma particularidade cultural dentro de um contexto multicultural.” Os surdos e os ouvintes encontram-se imersos em um mesmo espaço físico, compartilhando culturas, a cultura surda e a cultura ouvinte. Além disso, os aspectos de ambas as culturas se mesclam, o que torna os surdos indivíduos multiculturais.

Nesse sentido:

[...] é possível aceitar o conceito de Cultura Surda por meio de uma leitura multicultural, em sua própria historicidade, em seus próprios processos e produções, pois a Cultura Surda não é uma imagem velada de uma hipotética Cultura Ouvinte, não é seu revés, nem uma cultura patológica. (SKLIAR, 1998, p.28).

De acordo com o ator surdo Pimenta (2001, p.24) “[...] a surdez deve ser reconhecida como apenas mais um aspecto das infinitas possibilidades da diversidade humana, pois ser surdo não é melhor ou pior do que ser ouvinte é apenas diferente”. Ainda segundo o autor, o surdo possui "um jeito Surdo de ser” que se trata de uma cultura da visão, pois a língua de sinais é gestual - visual e as experiências dos surdos são através da visão.

A língua de sinais, assim como outras línguas, surgiu da necessidade de comunicação e das relações sociais da comunidade surda. Manteve-se viva no decorrer da história, mesmo com todas as proibições, demonstrando-se comparável a quaisquer outras línguas. Conforme Brito (1995, p.11),

[...] a LIBRAS é uma língua natural com toda a complexidade que os sistemas lingüísticos que servem à comunicação e de suporte de pensamento às pessoas dotadas da faculdade de linguagem possuem. É uma língua natural surgida entre os surdos brasileiros da mesma forma que o Português, o Inglês, o Francês, etc. surgiram ou se derivaram de outras línguas para servir aos propósitos lingüísticos daqueles que as usam.

Concordando com Brito (1995), Quadros (2004, p.30) afirma que “[...] as línguas de sinais são consideradas línguas naturais e, conseqüentemente compartilham uma série de características que lhes atribui caráter específico e as distingue dos demais sistemas de comunicação”.

Assim, para Kyle (1999) a língua de sinais é considerada a língua natural do sujeito surdo, pois se desenvolve em meio à comunidade surda de forma espontânea. Concordando com isso, Brito (1995, p.27) afirma que a língua de sinais 
[...] é adquirida de forma espontânea pela pessoa surda em contato com as pessoas que usam essa língua e se a língua oral é adquirida de forma sistematizada, então as pessoas surdas têm o direito de ser ensinadas na língua de sinais. A proposta bilíngüe busca captar esse direito.

Considerando que a L1 da pessoa surda é a língua de sinais, a língua portuguesa escrita é caracterizada diferentemente dos ouvintes para os surdos, sendo que Fernandes (2004, p.9) pontua que para os surdos, “[...] o português será uma segunda língua, sem referências linguísticas auditivas ou 'naturais"”.

Assim, Quadros (1997, p.111) enfatiza que

A Língua Portuguesa é a L1 de crianças ouvintes brasileiras e, necessariamente, deverá ser ensinada de forma diferente para crianças surdas que a adquirirão como L2. Além do fato de a língua portuguesa não ser a L1 do surdo, há a questão da diferença na modalidade das línguas. A criança surda deverá adquirir uma L2 que se apresenta numa modalidade lingüisticamente diferente da sua L1, isto é, ela deverá aprender uma língua 'gráfico-visual’ enquanto a sua L1 é ‘visual-espacial’. Os estudos sobre o ensino de L2 partem do pressuposto de que a criança estará adquirindo uma L2 na mesma modalidade lingüística de sua L1. Dessa forma, o ensino da L2 - Língua Portuguesa - para surdos apresenta questões mais complexas que exigem mais investigação. O processo de aquisição de uma L2 em crianças dependem de, no mínimo dois, pré-requisitos: (a) garantia de um processo natural de aquisição de uma L1 e (b) a aquisição da língua escrita, isto é, da alfabetização.

As pessoas surdas têm direito a uma educação bilíngue e, nesse sentido, Quadros (1997) define o bilinguismo como a educação que se propõe tornar acessível à criança duas línguas no contexto escolar. Seu objetivo é propiciar à criança surda um desenvolvimento cognitivo e linguístico equivalente ao verificado na criança ouvinte, desenvolvendo assim uma relação de harmonia com os ouvintes. Essa heterogeneidade deve ser vista como uma riqueza, uma oportunidade de aprendizado coletivo e não como um obstáculo.

Podemos afirmar então que os surdos são possuidores de uma língua que se apresenta na modalidade gestual-visual, diferentemente da língua portuguesa, que é oral auditiva, sendo, portanto bilíngues em línguas que se apresentam com modalidades distintas. Assim, Strobel (2008, p.46) afirma que “A língua de sinais não pode ser estudada tendo como base a língua portuguesa, 
porque ela tem gramática diferenciada, independente da língua oral. Sendo assim, “[...] a língua portuguesa não será a língua que acionará naturalmente o dispositivo devido à falta de audição da criança. Essa criança até poderá vir a adquirir essa língua, mas nunca de forma natural e espontânea como ocorre com a língua de sinais”. (QUADROS, 1997, p.27).

Constata-se, portanto, que a língua portuguesa é tida como uma língua artificial, como uma segunda língua sendo oral-auditiva distinta da modalidade da língua de sinais. Assim, percebemos que o contexto de aquisição bilíngue dos sujeitos surdos, acontece diferentemente das pessoas ouvintes. Esse contexto bilíngue dos não ouvintes acontece primeiramente, na maioria dos casos, no contexto escolar, pois de acordo com Fernandes (2004, p.5) "[...] 95\% das crianças são filhas de pais ouvintes, sendo muito pequeno o percentual de surdos filhos de pais surdos”. Dessa forma, normalmente os surdos filhos de pais ouvintes, crescem em meio a uma língua fragmentada, a língua portuguesa oral, da qual não podem se apropriar, pois há a barreira da falta de audição para a aquisição, e a língua de sinais na maioria das vezes não é conhecida pela família. O que normalmente acontece é que entre os surdos e a família são combinados sinais para estabelecer uma forma de comunicação e, é somente através do contato com outros surdos, que o surdo aprenderá a língua brasileira de sinais. Assim, diferente das crianças ouvintes que nascem e crescem num ambiente linguístico em que podem desenvolver a linguagem, as crianças surdas, em sua maioria, não tiveram oportunidade de ter um desenvolvimento pleno da sua linguagem, devido à carência de um ambiente linguístico nos primeiros anos de vida. Essa situação acarretará na dificuldade de aprendizado de uma segunda língua, pois se a primeira não está bem estruturada, como aprenderá uma segunda língua?

Somente a partir do momento que os surdos começam a interagir com outros surdos, é que a língua de sinais será aprendida de forma natural. Será em meio à comunidade surda que haverá o desenvolvimento linguístico, cultural e social, o que contribuirá para a formação de sua identidade. Porém, na maioria dos casos, a "descoberta" da surdez e o contato com a comunidade surda acontecem tardiamente o que prejudica o desenvolvimento linguístico do sujeito surdo. Os autores Padden e Humphriens (2000, p.16) afirmam que "Nas histórias que coletamos de crianças Surdas de pais Surdos, o mesmo padrão emerge mais e mais: a "surdez" é "descoberta” tardiamente... Não é surpreendente que a escola é geralmente o cenário para este tipo descobrimento", pois muitas vezes, quem detecta que o aluno possui alguma perda auditiva, são os 
professores e os encaminhamentos quanto a surdez, são feitos pela própria escola. A partir disso, a escola de surdos tem papel fundamental no trabalho com os pais para a aceitação da surdez, já que a família a encara através da visão patológica, como perda auditiva, como um filho "anormal”; e conforme Wrigley (1996, p.16) "Para aquele que ouve, a surdez representa uma perda de comunicação, a exclusão a partir de seu mundo”. Porém, os surdos não veem a falta de audição como um problema social, mas como algo natural, como mais um membro a integrar-se à comunidade surda, essa perspectiva faz parte da cultura surda.

Assim as escolas de surdos preconizam a proposta bilíngue, de maneira que ambas as línguas, a de sinais e a portuguesa escrita, sejam trabalhadas; aquela sendo a língua natural dos surdos e o meio de instrução, e esta, a língua portuguesa, sendo a segunda língua. Diante disso Quadros (1997) salienta que a proposta bilíngue deve considerar que a maioria dos surdos que chegam à escola, são filhos de pais ouvintes e que,

A criança precisa ter contato com surdos adultos. A presença de surdos adultos apresenta grandes vantagens dentro da proposta bilíngüe. Primeiro, a criança, tão logo tenha entrado na escola, é recebida por um membro que pertence à sua comunidade cultural, social e lingüística; assim, ela começa a ter oportunidade de criar a sua identidade. Segundo, essa criança começa a adquirir a sua língua natural. Tais vantagens são imprescindíveis para o sucesso da proposta bilíngüe. Deve haver um ambiente próprio dentro da escola (ou em outro lugar) para desenvolver a linguagem e o pensamento da criança surda; assim, tornar-se-á possível o ensino de uma segunda língua, caso contrário, a criança surda não terá chances de apresentar um domínio razoável da língua portuguesa. (Ibidem, p.30).

Sob essa visão, é imprescindível que desde a mais tenra idade, os surdos possam interagir com a comunidade surda, seja na escola ou na associação de surdos, a fim de que lhe seja oferecido o direito à aquisição de sua língua natural de forma espontânea, pois isso é fundamental para o seu desenvolvimento linguístico e cognitivo. Assim Strobel (2008, p.104) esclarece que

A criança surda necessita de professores surdos usuários de língua de sinais e cultura própria em seu processo de construção de identidade e educacional. O imaginado é que surdos tenham contato com outros 
surdos que constituem o povo surdo ${ }^{1}$, onde acontece o seu desenvolvimento como sujeito diferente, sendo um centro de encontro com o semelhante para que desenvolva sua identidade cultural, por isso estes defendem a importância de termos escola de surdos.

Assim, é necessário, que os pais ouvintes tenham a consciência da importância do aprendizado da língua de sinais para a comunicação com seu filho e, sobretudo, que dê a oportunidade a seu filho de interagir com a comunidade surda o mais cedo possível, para que assim possa ter um desenvolvimento linguístico.

Em relação ao contexto de aquisição e desenvolvimento linguístico da pessoa surda, Quadros (2008, p.31) esclarece que o “[...] contexto bilíngüe é completamente atípico de outros contextos bilíngües estudados, uma vez que envolve modalidades de línguas diferentes”; a língua portuguesa na modalidade oral-auditiva e, a língua de sinais que se apresenta na modalidade visual-espacial.

Nesse sentido, Quadros (Ibidem, p.29), afirma que para pensar no bilinguismo para os surdos, devem-se considerar aspectos relacionados à questão das modalidades distintas das línguas, pois essas se apresentam em modalidades diferentes. Além disso, o contexto familiar dos surdos é formado, na maioria dos casos, por pais ouvintes e esses desconhecem a língua de sinais. Outro fator importante é que, na maioria dos casos, a aquisição da língua de sinais ocorre tardiamente na vida dos alunos surdos. Normalmente isso acontece quando os alunos vão para a escola de surdos e passam a ter contato com outros surdos. No entanto, a língua de sinais tem status de primeira língua para os surdos. É importante salientar que ainda segundo a autora, “[...] a língua portuguesa apresenta uma ameaça para os surdos”, pois essa é a língua institucionalizada, sendo que "[...] as políticas públicas determinam que os surdos 'devem' aprender português”; porém os surdos lutam pelo direito de serem ensinados na sua primeira língua - a língua de sinais. Nesse sentido, Quadros (2008, p.29) afirma que há necessidade de “[...] revisão do status do português pelos próprios surdos: reconstrução de um significado social a partir dos próprios surdos”, de forma que o aprendizado da língua portuguesa seja tido como algo significativo para os surdos.

\footnotetext{
' “Quando pronunciamos 'povo surdo', estamos nos referindo aos sujeitos surdos que não habitam um mesmo local, mas que estão ligados por uma origem, por um código ético de formação visual, independente de grau de evolução lingüística, tais como língua de sinais, a cultura surda e quaisquer outros laços". (STROBEL, 2008, p.31). 
Percebe-se, portanto, que a constituição do contexto bilíngue para os surdos ocorre diferentemente dos ouvintes, sendo que o status de sujeito bilíngue deve ser analisado a partir dos vários fatores apresentados anteriormente.

A partir do exposto constatamos que o status de sujeitos bilíngues surdos parte da formação de um contexto bilíngue atípico - um bilinguismo construído diferentemente dos outros - e, de acordo com Quadros, (Ibidem, p.31) "[...] descobrir os laços de tais cruzamentos e das fronteiras que são estabelecidas é desafiador tanto para os surdos como para os ouvintes envolvidos”, e isso requer estudos e pesquisas mais aprofundados.

\section{Metodologia}

O trabalho foi realizado através de levantamento de bibliografias para o embasamento teórico. Depois, foi detectada uma situação de bilinguismo para fazer a descrição da situação encontrada e a pesquisa de campo com o indivíduo bilíngue. Para o sujeito, bem como a instituição observada, foram utilizados nomes fictícios a fim de se preservar a identidade de ambos. $\mathrm{O}$ contexto bilíngue escolhido foi o da aluna Bianca que cursa o Magistério no Colégio A. A estudante Bianca foi observada durante alguns dias e em especial durante a realização de uma prova de Fundamentos Históricos da Educação.

\section{Resultados e discussão}

Durante a observação da situação bilíngue da aluna Bianca, verificouse que um intérprete de língua de sinais a acompanhava durante todas as aulas, estabelecendo a compreensão da aula do professor que era feita de maneira oral, traduzida para língua gestual-visual. O estudo, os exercícios e provas eram escritos, o que requer do surdo um maior domínio do vocabulário escrito da língua portuguesa. A aluna Bianca é surda profunda, isto é, não possui resíduo auditivo.

Durante a realização da prova de Fundamentos Históricos da Educação, a intérprete solicitou que Bianca lesse e respondesse a questões que eram objetivas e discursivas, respondendo-as a lápis. A aluna respondeu algumas (principalmente as objetivas) e deixou em branco as discursivas, dizendo que 
não as entendeu. Após isso, Bianca respondeu o que conseguiu da prova; a intérprete, então, traduziu em língua de sinais cada questão da prova, solicitando que a aluna observasse suas respostas. Percebeu-se que quando a prova foi lida em Libras a aluna se deu conta de que havia errado algumas questões e que depois de interpretadas as questões discursivas, a aluna soube respondê-las.

Na situação observada, pode-se notar a grande dificuldade da aluna em compreender a parte escrita prova. O domínio da língua portuguesa escrita pela aluna é restrito, principalmente porque cada disciplina possui vocabulário próprio, e a leitura de textos, provas e atividades requer uma maior explicação por parte do intérprete.

Sendo a língua de sinais de estrutura gramatical diferente da língua portuguesa e numa modalidade espaço-visual, o aluno surdo escreve somente o que tem sentido em língua de sinais, omitindo preposições, artigos, concordância verbal e nominal, flexão verbal, dentre outras. Dessa maneira, na leitura de um texto identifica as palavras que fazem parte de seu vocabulário, muitas vezes não compreendendo gírias e as entrelinhas dos enunciados. Assim, é necessário que o intérprete explique de forma que o aluno compreenda o sentido do texto.

Apesar de Bianca ser muito independente, requer um acompanhamento mais próximo do intérprete e um estudo mais aprofundado dos vocabulários, que muitas vezes são considerados simples pelas pessoas ouvintes. Percebeuse que o conteúdo aplicado na prova era dominado pela aluna, tanto que em língua de sinais sabia explicar as repostas das questões abordadas. Porém a dificuldade estava em entender o que para ela é sua segunda língua, a língua portuguesa.

Quanto à entrevista em relação a ser uma pessoa bilíngue, quando o intérprete sinalizou a palavra bilinguismo, Bianca identificou-se conhecedora do sinal. Ao ser questionada se era uma pessoa bilíngue, ficou em dúvida, não sabia responder com precisão. O intérprete então explicou o que seria bilinguismo dando exemplos, e logo Bianca afirmou ser bilíngue, dizendo que sabia a língua de sinais e a língua portuguesa escrita.

Quanto às dificuldades apontadas pela aluna entrevistada, podemos elencar as mais abordadas:

a) Dificuldade no entendimento de textos e provas devido ao desconhecimento de alguns vocabulários da língua portuguesa; 
b) Quando o professor escreve os conteúdos no quadro, explicando juntamente, o surdo não sabe se copia ou olha para o intérprete. O ideal é que se passe o conteúdo todo no quadro e após a cópia, ocorra a explicação;

c) Quando o professor explica o conteúdo fazendo apontamentos e esquemas no quadro, deve dar um tempo após a explicação para que o surdo copie, pois se o surdo fizer a cópia durante a exposição oral do professor, perderá o conteúdo da explicação;

d) Palavras específicas de uma área do conhecimento (exemplo: vocabulários de biologia, geografia, informática, etc.) que não existem ou que os surdos desconheçam os sinais em Libras, dificultam o aprendizado, pois a soletração por si não tem sentido para o surdo, e no momento da prova escrita são cobrados que se saibam a palavra e se explique os conceitos com os termos peculiares ao conteúdo.

\section{Conclusão}

A constituição do contexto bilíngue para surdos conforme visto acontece de forma diferenciada dos ouvintes. Várias questões devem ser levadas em conta, como a situação tardia de aquisição da língua de sinais pelos surdos, que se dá normalmente quando os sujeitos surdos entram em contato com a comunidade surda na escola de surdos, sendo que esse contato tardio prejudica o desenvolvimento linguístico das crianças surdas; e, obviamente, a questão da língua portuguesa, que é considerada segunda língua para os surdos.

Os surdos e sua comunidade possuem uma maneira peculiar de apreender o mundo. Suas experiências e aprendizado são construídos através da visão, seu mundo é constituído diferentemente dos ouvintes, conforme Pimenta (2001) destaca, constitui um "jeito Surdo de ser”, uma “cultura da visão”.

Dentro da proposta de educação bilíngue abordada nas escolas, temos a possibilidade de vivenciar a pluralidade cultural com a aproximação das diferenças, a língua como um encontro multicultural, no qual por meio da língua de sinais como primeira língua, promove-se o desenvolvimento da língua portuguesa como uma segunda língua para a pessoa surda. Porém, é importante ressaltar que não se trata simplesmente da transferência de uma língua para outra, existem aspectos linguísticos diferenciados que devem ser estudados, analisados e respeitados. 
Diante de contextos bilíngues em sala de aula, o professor deve ter a postura a fim de reconhecer o comportamento dos alunos em relação às crianças de diferentes históricos linguísticos e sociais, salientando que somos culturais. É importante ressaltar que não há língua melhor ou pior, todas são igualmente importantes. Se não tivéssemos a "diferença”, o mundo se limitaria a reproduzir o mesmo e o idêntico, seria então um mundo parado e igual. No entanto, respeitar e valorizar as diferenças étnicas, sociais e linguísticas, não significa aderir valores, mas sim respeitá-los, o que é devido a todo o ser humano.

A diversidade é uma riqueza em sala de aula e o professor deve aproveitá-la a fim de proporcionar situações contextualizadas de interação aluno x professor e aluno x aluno, propiciando assim, trocas culturais e linguísticas, enriquecendo ainda mais o ambiente escolar, tornando a sala de aula mais autêntica, buscando a eliminação das barreiras linguísticas e culturais. Para o aluno surdo, a presença do intérprete de língua de sinais é imprescindível para a compreensão do surdo, pois ele é o elo da comunicação professor versus aluno, garantindo aos surdos a acessibilidade ao conteúdo. Quanto à língua portuguesa escrita, essa é uma segunda língua para os surdos e eles detêm apenas vocabulários que tem sentido em língua de sinais. É normal, por exemplo, o intérprete de língua de sinais, em meio a uma tradução, abrir um "parênteses" em sua interpretação e explicar algum termo não compreendido e/ ou desconhecido pelo aluno surdo, principalmente no que se refere à escrita.

Em relação à avaliação escolar e à língua portuguesa, percebemos que o professor deve utilizar critérios diferenciados para avaliar o que o aluno produziu na escrita, levando em consideração que essa é uma língua estrangeira para os surdos e que a escrita dos surdos apresenta as características da estrutura da língua de sinais. Sendo assim, as diferenças linguísticas devem ser respeitadas de forma a valorizar a língua e a escrita do aluno, buscando alternativas diferenciadas para uma avaliação mais justa que realmente reconheça e respeite as diferenças. Sabe-se que a situação educacional dos surdos os coloca em desvantagem com os ouvintes em relação às práticas linguísticas. As práticas avaliativas desenvolvidas no contexto escolar buscam para os surdos os mesmo resultados ou desempenho esperado dos ouvintes, o que desencadeia um processo de expulsão silenciosa. Carecemos, ainda, de uma política linguística oficial, séria e comprometida, que incorpore um projeto educacional de princípios norteadores que valorizem a língua de sinais e respeitem as diferenças linguísticas e culturais dessa língua. 
De acordo com Eva Engholm (1965, apud MELLO, 1999, p.7), no livro O Falar Bilíngüe, “A língua é a chave para o coração de um povo. Se perdermos a chave, perderemos o povo. Se guardarmos a chave em lugar seguro como um tesouro, abriremos as portas para riquezas incalculáveis, riquezas que jamais poderiam ser imaginadas do outro lado da porta”. Nesse sentido, cabe a nós aceitarmos a língua de sinais e a pessoa surda, não buscando mudálos, mas sim ajudá-los, ensiná-los e permitir-lhes "ser surdos”, reconhecendo sua língua, identidade e cultura, pois somente assim estaremos buscando uma sociedade mais igualitária que realmente respeite as diferenças.

\section{Referências}

BRASIL. Constituição da República Federativa do Brasil: de 5 de outubro de 1988. 13 ed. São Paulo: Atlas, 1990, 304p.

BRASIL. Lei de diretrizes e bases da educação nacional: texto na íntegra: lei n. 9.394, de 1996. Brasília: Saraiva, 1996. 34p.

BRASIL. Lei Federal n. 10.436, de 24 de abril de 2002. Dispõe sobre a Língua Brasileira de Sinais - Libras e dá outras providências. Disponível em: <www.planalto.gov.br/ccivil/ leis/2002/L10436.htm>. Acesso em: 8 jun. 2009

BRASIL. Parâmetros Curriculares Nacionais: pluralidade cultural, orientação sexual/ Secretaria de Educação Fundamental. Brasília: MEC/SEF, 1997.164p.

BRITO, Lucinda Ferreira. Por uma gramática de língua de sinais. Rio de Janeiro: Templo Brasileiro, UFRJ, Departamento de Lingüística e Filologia, 1995.

FERNANDES, Sueli. Educação bilíngue para surdos: trilhando caminhos para a prática pedagógica. Curitiba: SEED, 2004.

KELMAN, Celeste A. Multiculturalismo e surdez: uma questão de respeito às culturas minoritárias. In: FERNANDES, Eulália (Org.). Surdez e bilinguismo. Porto Alegre: Mediação, 2008.

KYLE, J. O ambiente bilíngüe: alguns comentários sobre o desenvolvimento do bilingüismo para surdos. In: SKLIAR, C. (Org.). Atualidades da educação bilíngue para surdos. Porto Alegre: Mediação, 1999. p.15-26.

MELLO, Heloísa Augusta Brito de. O falar bilíngue. Goiânia: Ed. da UFG, 1999.

QUADROS, R. M. O ‘BI’ em bilingüismo na educação de surdos. In: FERNANDES, Eulália (Org.). Surdez e bilinguismo. Porto Alegre: Mediação, 2008. 1997.

. Educação de surdos: a aquisição da linguagem. Porto Alegre, Artes Médicas,

A língua de sinais brasileira: estudos lingüísticos. Porto Alegre, Artmed, 2004. 
PADDEN, Carol; HUMPHRIENS, Tom. Deaf in America: voices from a culture. Cambridge, Massachusetts; Londres, Harvard University Press, 2000.

PIMENTA, N. Oficina-palestra de cultura e diversidade. In: SEMINÁRIO NACIONAL DO INES, 8. Anais. Rio de Janeiro: INES, 2001.

STROBEL, Karin Lilian. As imagens do outro sobre a cultura surda. Florianópolis: Editora da UFSC, 2008.

SKLIAR, Carlos (Org.). A surdez: um olhar sobre as diferenças. Porto Alegre: Mediação, 1998.

WRIGLEY, Oliver. Política da surdez. Washington: Gallaudet University Press, 1996.

Recebido para publicação em 30 junho 2009

Aceito para publicação em 01 dezembro 2009 